ISSN $0819-2642$

ISBN 9780734040077

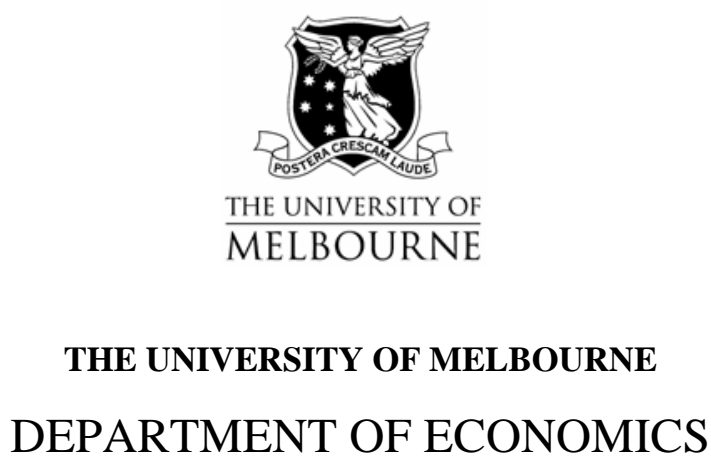

RESEARCH PAPER NUMBER 1041

May 2008

The Human Development Index as a Criterion for Optimal Planning

by

Merwan Engineer, Ian King \& Nilanjana Roy

Department of Economics

The University of Melbourne

Melbourne Victoria 3010

Australia. 


\title{
The Human Development Index as a Criterion for Optimal Planning*
}

\author{
Merwan Engineer ${ }^{1}$ \\ Ian King $^{2}$ \\ Nilanjana Roy ${ }^{1}$
}

May 2008

\begin{abstract}
Planning strategies that maximize the Human Development Index (HDI) tend towards minimizing consumption and maximizing non-investment expenditures on education and health. Interestingly, such strategies also tend towards equitable outcomes, even though inequality aversion is not modelled in the HDI. A problematic feature of strategies that maximize the HDI is that the income component in the index only role is to distort the allocation between health and education expenditure. Because the income component does not play its intended role of securing resources for a decent standard of living, we argue that it is better to drop income from the index in considering optimal plans. Alternatively, we consider net income, income net of education and health expenditures, as indicator of capabilities not already reflected in the education and life expectancy components of the index. When net income is used in a modified HDI index, optimal plans yield a balance between allocations for consumption, education, and health. Finally, we calculate our modified indexes for OECD countries and compare them with the HDI.
\end{abstract}

Keywords: Consumption; Human development index; Income; Inequality; Planning

JEL classification: $\mathrm{O} 21$; $\mathrm{O} 15$

\footnotetext{
${ }^{1}$ Department of Economics, University of Victoria, Victoria, Canada.

${ }^{2}$ Department of Economics, University of Melbourne, Melbourne, Australia.
}

*We would like to thank Achin Chakraborty, Yehuda Kotowitz, Lars Osberg, Les Oxley, and participants at the 2007 Canadian Economics Meeting in Halifax, University of Otago and University of Victoria for comments. We would also like to thank the Social Sciences and Humanities Research Council of Canada for financial support. 


\section{Introduction}

The Human Development Index (HDI) is a composite index published annually by the UN Human Development Report Office, since 1990, which is designed to measure "human well being" in different countries. ${ }^{1}$ The index combines measures of life expectancy, school enrolment, literacy, and income to provide a broader-based measure of well-being and development than income alone. Since its publication, this index has become widely cited and is commonly used as a way of ranking the quality of life in different countries.

The impact of the HDI ranking on policy is reflected by the fact that some national governments have taken to announcing their HDI ranking and their aspirations for improving it. For example, in a recent speech, the President of India, Dr. Abdul Kalam, exhorts Indians to work together to improve India's current HDI rank of 127 to achieve a rank of 20; see Kalam (2005). The HDI is discussed in recent Indian budgets (e.g. Budget of India (2005)) and changes in India's ranking are covered by the media (e.g. Parsai (2006)). In announcing Canada's number one ranking in 1998, Prime Minister Jean Chrétien stated: "While the HDI tracks Canada's impressive achievements, it also tells us where we can improve.” (Chrétien (1998)).

In this paper, we consider the implications of using the HDI as a criterion for economic development plans. In particular, we examine the consequences of pursuing plans that maximize the HDI score for a given country. To do this, we construct an economic model where a planner chooses expenditures to maximize a well-defined objective function that includes the HDI index as a special case. ${ }^{2}$ We get two main results. First, the planner tends towards minimizing consumption and maximizing expenditures on education and health. We get this result despite the fact that the HDI includes an income index as one of its components. Second, the optimal plan tends to imply equitable outcomes even though inequality aversion is not explicitly modelled in the HDI. This latter result is arguably a surprisingly beneficial consequence of using the HDI that addresses the concern for equity expressed in the Human

\footnotetext{
${ }^{1}$ For a detailed description see http://hdr.undp.org/statistics/indices/.

${ }^{2}$ Bourguignon and Fields (1990) apply a similar methodology. They minimize various poverty indexes subject to redistribution constraints and show that the implied policies can differ radically depending on the index.
} 
Development Reports and literature (e.g. Anand and Sen (2000)). In contrast, the first result leads to what we consider to be a flaw with the HDI, but one that can be readily fixed.

The first result - that the planner tends towards minimizing consumption and maximizing expenditure on education and health - describes a lopsided allocation. The reason for the lopsided allocation is that consumption does not enter the index (the objective function) or the production technology, but costs the planner through the resource constraint, so the optimal plan will set consumption to meet minimum consumption requirements. From another perspective this lopsided allocation arises because the income component in the HDI only has one role in the optimal plan and that is to indirect affect the allocations of funds between education and health.

The logic of the first result can be readily explained in our basic model where income can be decomposed into expenditures on consumption, education and health. As consumption is at its minimal level, the remaining expenditures are allocated to education and health. Education and health expenditures are valued directly in those components of the HDI and are also valued in the income component. The HDI is flawed because the income component "double counts" the value of allocating expenditures to education and health and because it does not effectively value expenditures on other items.

For these reasons we argue that it is better to drop income from the index in considering optimal plans rather using the HDI as it stands. However, this falls short of the original vision for the HDI as an overall composite index. The income component of the HDI was originally justified as an indirect proxy of "command over resources to enjoy a decent standard of living" (Human Development Report 1990, p. 1). Anand and Sen (2000, p. 86) state:

The use of 'command over resources' in the HDI is strictly as a residual catch-all to reflect something of other basic capabilities not already incorporated in the measures of longevity and education. ... For example, going hungry is a deprivation that is serious not just for its tendency to reduce longevity, but also for the suffering it directly causes. Similarly, resources needed for shelter and for being able to 
travel may be quite important in generating the corresponding capabilities.

In the later part of the paper we argue for a modified HDI that replaces the income component with a net income component; i.e. income that is net of expenditures on education and health. Plans that maximize the modified index directly trade-off the allocations to consumption, education and health against each other. This leads to plans that balance expenditures across the three components.

Using data OECD countries we construct and calculate a modified human development index with net income component as well as a modified human development index without an income component. The rank orderings of nations given by these modified indexes is compared with the HDI. Interestingly, the modified index without income yields the greater change in rankings with a few countries standing out.

The paper continues as follows. Section 2 develops the model. Section 3 solves the planner's problem, and Section 4 explores equity and taxation issues. Section 5 examines the role of income in the HDI index, and provides a critique of the income component. Section 6 compares the modified human development indexes both theoretically and empirically with the HDI. Section 7 concludes. All proofs are found in the Appendix.

\section{The model}

We consider a static closed economy model, where a planner acts to maximize the following objective function, which nests the HDI:

$$
I(w, W)=w I^{y}(y)+(1-w)\left[W I^{e}(e)+(1-W) I^{l}(l)\right]
$$

Here, $I^{y}(y), I^{e}(e)$, and $I^{l}(l)$ represent indexes of per capita income $(y)$, educational attainment $(e)$, and life expectancy $(l)$ respectively. The indexes are each bounded between 0 and 100, and are assumed to be differentiable, increasing and concave in 
their respective arguments. ${ }^{3}$ The weights parameters $w$ and $W$ are used when constructing the composite index, in equation (1). We give income a separate weight because we concentrate on that part of the index. Observe that the index can be rewritten $I(w, W)=w I^{y}(y)+(1-w) I(W)$, where $I(W)=W I^{e}(e)+(1-W) I^{l}(l)$ part o the index not containing income. The HDI is a special case of this index, where $w=$ $1 / 3$ and $W=1 / 2$, so that each of the three component indexes are equally weighted.

Educational attainment is assumed to be a differentiable increasing function of expenditures on both education $(E)$ and health $(H)$. Thus:

$$
e=e(E, H), \quad e_{E}>0, \quad e_{H} \geq 0
$$

Similarly, life expectancy is differentiable and increasing in both of these arguments ${ }^{4}$ :

$$
l=l(E, H), \quad l_{E} \geq 0, \quad l_{H}>0, \quad l(0,0)>0
$$

To simplify the analysis, we are assuming that the economy in question has a level of per capita income high enough so that neither income nor consumption substantially affect life expectancy and educational attainment as measured in the HDI. This is formalized by the following assumption about individual consumption $c$ :

$$
C \geq C_{\min }
$$

where $C_{\min }>0$ is a parameter which identifies the level of consumption beyond which no further increments in consumption will increase educational attainment or life expectancy. ${ }^{5}$ Later we relax constraint (4) and show that the results become stronger.

\footnotetext{
${ }^{3}$ In the HDI the income of $\$ 100$ US corresponds to the index being 0 and the "goalpost", of $\$ 40,000$ US corresponds to the index being 100. As of 2004 two countries, the US and Luxembourg, had achieved the \$40,000US goalpost. The income index is logarithmic in income between the bounds. The education and life expectancy indexes are linear in their variables. The education variable $e$ is a linear combination of literacy rates and school enrolment rates, and as of 2004, there were 5 countries that scored enrolment rates that yielded 100 on this index. No country has achieved the goalpost for life expectancy, which is currently 85 . No country is at the lower bound for any of the indexes. Our analysis goes through for any country as long as there is at least one index that falls short of 100. Indeed, we do not even need concavity for our results but assume it for simplicity.

${ }^{4}$ We have taken the short cut of specifying life expectancy (education) as a function of education (health) expenditure rather than education (health) attainment. Functions (3) and (4) can be shown to be consistent with the more general specification under minor restrictions. Assuming that minimum life expectancy is positive simplifies the analysis.

5 This assumption is consistent with Anand and Ravallion's (1993) "capability expansion through social services". According to this explanation (also see Sen, 1981), the public provision of essential goods and services leads to improved social outcomes and income matters if it is used to finance suitable public services and alleviate poverty. For example, Anand and Ravallion find in a sample of
} 
In this simple static economy, we abstract away from capital and assume full utilization of labour. All individuals' work and the total number of workers in the economy is normalized to one unit. Given this, output per capita is determined by the following differentiable production technology:

$$
y=f(e, l), \quad f_{e} \geq 0, \quad f_{l} \geq 0
$$

Here, education attainment affects output through human capital in the usual way. Also, increments in life expectancy increase the effective size of the labour force and thereby increase production. Increments in life expectancy can be thought to increase the effective size of the labour force in two ways: directly through increasing the possible amount of work time per individual over a life time and indirectly by indicating better health and hence greater productivity.

Once produced, the single good in the economy can be allocated to three possible uses: aggregate consumption $(l \cdot c)$, education expenditure $(E)$, and health expenditure $(H)$. Therefore, the economy must respect the aggregate constraint:

$$
l c+E+H \leq y
$$

Observe that consumption, $c$, is on items other than health and education and that we allow total consumption to be proportional to life expectancy. We only analyze situations where there is at least one feasible allocation $(c, E, H)$ satisfying equations 2-6 and the non-negatively constraints $E \geq 0$ and $H \geq 0$. A sufficient condition for this is that $l c_{\min } \leq y$ when $E=H=0$; i.e. minimum output can meet minimum consumption at minimum life expectancy.

\section{Efficiency}

22 developing countries that after controlling for health expenditures and poverty (as measured by the proportion of population consuming less than one dollar per day in 1985 at PPP), life expectancy is not affected by consumption. Even the unconditional plot of income against life expectancy displays an income threshold (roughly 10,000 US dollars at purchasing power parity) beyond which there is no discernable relationship (e.g. Deaton, 2003)). Anand and Ravallion contrast schools of thought on the importance of social services versus private consumption for human development. 
Using equations 1-6, the planner's problem can be formulated as the programming problem (P1):

$$
\begin{aligned}
& \underset{\{c, E, H\}}{\operatorname{Max}} I(w, W)=w I^{y}(f(l(E, H), e(E, H)))+(1-w)\left(W I^{e}(e(E, H))+(1-W) I^{l}(l(E, H))\right) \\
& \text { subject to: i) } \quad l(E, H) c+E+H-f(l(E, H), e(E, H)) \leq 0 \\
& \text { ii) } \quad-c \leq-c_{\min }
\end{aligned}
$$

Proposition 1. In the planner's problem, incremental reductions in consumption, $c$, towards $c_{\min }$ increase the HDI score. Maximizing the HDI requires setting consumption at the minimum level, $c^{*}=c_{\min }$, and allocating the remaining output to education and health expenditure, $E^{*}+H^{*}=y^{*}-l^{*} C_{\min }$.

The intuition behind these "efficiency" results is quite straightforward. Consumption does not enter the objective function or the production technology, but costs the planner through the resource constraint. Thus, reductions in consumption that are optimally allocated to education and health expenditures will increase the HDI. The optimal plan will set consumption to its minimal allowed value. Our formulation with a minimum consumption requirement clearly reveals that all remaining resources are allocated to those expenditures, education and/or health, which increase the objective function. $^{6}$

The fact that the minimum consumption constraint is binding at the optimum implies that in the absence of the consumption constraint that the planner would allocate even less to consumption and more to expenditures on education and health; i.e. if $c^{*}<c_{\min }$ then $E+H=y-l c^{*}>y-l c_{\min }$. Indeed, without the constraint, the planner's optimal choice would be $c^{*}=0$ so that $E^{*}+H^{*}=y^{*}$. This unrealistic corner solution arises only because we have excluded consumption from the education, health and production functions. But this exclusion was on the grounds that $c \geq c_{\min }$ is

\footnotetext{
${ }^{6}$ While the optimal plan heavily emphasizes expenditures on education and health, it does not involve maximizing the combined expenditure $E+H$. Recall from the resource constraint that $E+H=y-l c_{\min }$ so that maximizing $E+H$ is the same as choosing $E$ and $H$ to maximize $y-l c_{\min }$ subject to the resource constraint. The planner's problem yields the same outcome as this special case in two instances: (1) when $l_{E}=l_{H}=0$ and $w \rightarrow 1$ so that the planner maximizes output, and (2) when $l$ is at its upper bound so that all remaining expenditures go to education which is the only way to increase output.
} 
sufficiently high not to affect these functions. If consumption $c<c_{\min }$ has a sufficiently positive effect (on any of education, health, or production) then the optimal choice would be $c^{*} \in\left(0, c_{\min }\right)$ in the absence of the constraint. Minimal output is allocated to consumption when consumption plays an instrumental role and is not valued directly.

Even under our simplifying assumption $c \geq c_{\min }$, the stark result $c^{*}=c_{\min }$ needs further qualification. Most obviously, we have assumed that there is sufficient income for this is to be a feasible allocation. Less obvious our result depends on the efficacy of expenditures on investment and on improvements in education and health being valued by the planner; i.e. we have assumed that $e_{E}>0$ and $l_{H}>0$ as well as $I_{e}{ }^{e}(e)>0$ and $I_{l}^{l}(l)>0$. These conditions ensure that the shadow prices of expenditures on education and health are always positive. Then we get the result $c^{*}=c_{\min }$ because the shadow price of consumption is zero. ${ }^{7}$ It is sufficient for our result that one of the shadow prices for education and health be positive. In the HDI no country has reached the upper bound of 85 year so that the life expectancy index is below its upper bound, $I^{l}(l)<100$. At the same time is it appears that in even the riches countries that further health expenditures (and even education expenditures on health) are efficacious for life expectancy. We conclude that we can specify reasonable assumptions for establishing Proposition 1.

\section{Equity}

Probably the most common concern with the HDI is that it only uses average per capita income and, therefore, is consistent with large income disparities within countries. Thus, two countries with the same average income would be scored the

\footnotetext{
${ }^{7}$ More elaborate models yield the same result. For example, our static formulation with full employment does not consider the possibility that persons do not work for a portion of their life, say beyond a retirement age, $R$, so that the amount of lifetime work is $\max [l, R]$. When life expectancy exceeds the retirement age, $l>R$, this might lead to $f_{l}=0$ at the margin (if there are no productivity benefits associated with greater life-expectancy). Still the objective function is increasing in $E$ and $H$ so that the resource constraint binds and the proposition obtains.

If we use a rate of consumption $y / l$ instead of $y$ in the objective function, the objective function would be increasing in $y / l$ as long as the elasticity $f_{l} l / f>1$ which is arguably empirically plausible. If $f_{l} l / f<1$, then we need to assume some technical conditions that assure that at least one of the shadow prices on $E$ or $H$ is always positive to prove the proposition.
} 
same by the index ceteris paribus, even though one country might have far more poor whose meagre 'command over resources' substantially inhibits their human development. For this reason that Anand and Sen (2000), Foster et al (2005) and others have argued that some sort of income inequality aversion should be built into the index explicitly. What seems to be missing in the literature is an analysis of how policies that promote human development as measured by the HDI affect inequality.

Our analysis has the surprising implication that policies that maximize the HDI score should dramatically reduce consumption inequality, ceteris paribus. The optimal policy according to Proposition 1 requires $c^{*}=c_{\min }$. This implies the optimal plan is egalitarian, at least with respect to consumption, even though no inequality aversion appears explicitly in the HDI itself. Though income inequality may still remain in a market economy, consumption inequality is what matters since a government following the optimal plan with access to non-distortionary taxation would tax away all disposable income leaving $c^{*}=c_{\min } .^{8}$

To make the argument formally, we model individuals and derive how the planner would allocate expenditures for them. Suppose there are $i=1,2, \ldots N$ individuals in the economy and each has a corresponding consumption constraint

$$
c_{i} \geq c_{\min }(i)
$$

Further, education and life expectancy expenditures and attainments might be distinguished by individual:

$$
\begin{aligned}
& e_{i}=e_{i}\left(E_{i}, H_{i}, E, H\right) \\
& l_{i}=l_{i}\left(E_{i}, H_{i}, E, H\right)
\end{aligned}
$$

\footnotetext{
${ }^{8}$ In practice, the government may only have distortionary tax instruments, in which case it we would have a second-best problem. In order to maintain a high level of income, the government would have to set taxes in a way that leaves those with higher incomes greater disposable income. We have chosen to not fleshing out the second-best problem as this would involve specifying a detailed microstructure to the problem and the particular results would depend on the particular microstructure used. Second-best problems in taxation are well known to limit the ability of government to implement allocations.
} 
where these functions are non-decreasing in all their arguments (and strictly increasing in at least one argument) and include aggregate values

$$
E=\frac{1}{N} \sum_{i=1}^{N} E_{i} \text { and } H=\frac{1}{N} \sum_{i=1}^{N} H_{i}
$$

to capture any external effects. The planner only cares about individual allocations insofar as they improve average output, education and life expectancy:

$$
y=f(e, l), e=\frac{1}{N} \sum_{i=1}^{N} e_{i} \text {, and } l=\frac{1}{N} \sum_{i=1}^{N} l_{i}
$$

The following proposition considers homogenous individuals. In our model, individuals are homogenous if they have the same minimum consumption needs, $\mathrm{c}_{\min }(\mathrm{i})=\mathrm{c}_{\min }$, and their education and life expectancy functions are of the same form, $e_{i}=e\left(E_{i}, H_{i}, E, H\right)$ and $l_{i}=l\left(E_{i}, H_{i}, E, H\right)$.

Proposition 2. Consider an economy of homogenous individuals.

(a) Maximizing the HDI requires setting $c_{i}^{*}=c_{\min }$ for all individuals so that the society is egalitarian with respect to consumption.

(b) Incremental reductions in average consumption increase the HDI score but need not be consumption inequality reducing.

(c) Maximizing the HDI yields completely egalitarian outcomes for consumption, education and life expectancy, when the education and life expectancy attainment functions are strictly concave.

Both 2(a) and 2(b) are generalizations of Proposition 1. However, there is an important proviso in 2(b): incremental reductions in average consumption may not reduce inequality. This follows simply from the fact that a reduction in average consumption can be achieved by reducing the consumption of a subset of individuals. The scope for dispersion in individual consumption narrows as average consumption approaches the minimum. In 2(c) egalitarian outcomes extend to education and health when there are diminishing returns to individual expenditures on education and health. ${ }^{9}$ Overall, Proposition 2 indicates that, if governments use the existing HDI as

\footnotetext{
${ }^{9}$ The analysis assumes that education and health are to an extent rivalrous. If they are considered pure public goods, $e_{i}=e(E, H)$ and $l_{i}=l(E, H)$, egalitarian outcomes obtain without assuming diminishing
} 
an objective function to devise their plans, then this leads to equitable outcomes through the implied emphasis on maximizing funding to education and health.

Observe that our complete egalitarian result is due to the concavity of the attainment assumptions and does not spring from either imposing horizontal equity or from a Utilitarian specification. Of course, deviations from egalitarianism would be optimal to the extent that agents are heterogeneous. However, since the index only incorporates averages, optimal plans lead to equality of treatment in the sense that the planner doesn't care about the identity of individuals except for identifying their consumption, education and health needs. Recall that the minimum consumption was motivated as being sufficiently high such that consumption did not impact the education, health or production functions. If the constraint was relaxed (as described in Section 3), the optimal plan would allocate consumption instrumentally by equating and individual's marginal benefit of the consumption (in terms of the increase in education, health and production) to the marginal resource cost.

\section{Critique of the Role of Income}

The income index $I^{y}(y)$ in the HDI was originally justified as an indirect proxy of "command over resources to enjoy a decent standard of living" (Human Development Report 1990, p. 1). Here we argue that income is a poor proxy for this purpose.

The emphasis on education and health expenditures in optimal plans naturally leads us to consider what role income plays in the HDI. In the optimal plan, given that $c^{*}=$ $C_{\min }$, the remaining problem of how to allocate resources to $E$ and $H$ is affected by $I^{y}(y)$ only because of the effects of $E$ and $H$ on production, indirectly through life expectancy $l(E, H)$ and education $e(E, H)$. By way of contrast, both $l(E, H)$ and $e(E, H)$ have direct impacts on the indexes $I^{e}(e)$, and $I^{l}(l)$ respectively. This reasoning is formalized in the following proposition.

returns. If education and health facilities are equally accessible to everyone in the economy, perhaps because of their public good nature, then maximizing the HDI implies equality of treatment though not necessarily outcomes among heterogeneous individuals. 
Proposition 3. Consider the weight $w<1$ on the income index $I^{y}(y)$ in the HDI.

(a) When $f_{l}>0$ or $f_{e}>0$, the weight $w$ affects only the trade-off between expenditures on education $E$ and health $H$.

(b) When $f_{l}=f_{e}=0$, the weight $w$ is irrelevant in determining the optimal plan.

In the general case 3(a), the way that changing $w$ affects the trade-off between $E$ and $H$ is complicated and ambiguous, since it depends on all partial derivatives of the functions. In special case 3(b), changing $w$ has no affect on the optimal plan so that $I(w, W)$ and $I(W)$ yield same optimal plan. Recall that $I(W)$ is the part of the index that excludes the income component. Hence in this special case, optimal plans are determined solely on the basis of parameter $W$, the relative weight on education versus health. ${ }^{10}$

Another way to see the problematic role of income is to examine how increases in output are apportioned. In the basic model $y=l \cdot c_{\min }+E+H$ and income growth does not affect the individual rate of consumption, $c$. Rather, $\Delta y=\Delta(E+H)+\Delta l \cdot c_{\min }$, so that output growth is correlated with expenditures $E+H$ and longevity $l$. Thus, the income component leads to the direct double counting of life expectancy. As the income component includes the inputs that increase $e(E, H)$ and $l(E, H)$, it indirectly double counts education and life expectancy.

\section{Comparing the HDI with and without the Income Component}

One response to our critique -- that the HDI effectively discounts the influence of income - might be that it is good news. Some who advocate the human development approach are critical of role of income in the index on the basis that it isn't an achievement or functioning per se but an indirect proxy. ${ }^{11}$ They are primarily

\footnotetext{
${ }^{10}$ In the HDI, the education and income indexes have the same weight, $W=(1-W)=1 / 2$. However, this does not imply that expenditures are equal on education and health. First, the resource constraint $E+H$ $=f-l c_{\min }$ reveals that increasing in life expectancy have the cost of overall increasing consumption. This feature discourages expenditures that enhance life expectancy compared to education. Second, the education and health indexes are not necessarily symmetric nor are the achievement functions $e(E, H)$ and $l(E, H)$.

${ }^{11}$ The human development approach, or equivalently the "capabilities approach", de-emphasizes valuing income per se [e.g. Sen (1985), Anand and Ravallion (1993)]. Anand and Ravallion (1993, p.136-37) note that while the philosophy of the Human Development Report has been heavily
} 
concerned with how income is converted to education and health achievements. Proposition 3 reveals that with optimizing behaviour, the weight on income $w$ is not at the expense of pursuing education and health improvements. However, if income were not a desirable objective it would be clearer and simpler to exclude it explicitly from the HDI. Generally, $w$ affects the division of resources to education and health and in complicated ways. Only in the special case when $f_{l}=f_{e}=0$ is the weight on income $w$ irrelevant to the division of resources.

Our analysis can be used to support the view that income plays a problematic role in the HDI and should be excluded from the index. To see this suppose $W$ is the true relative weight on education relative to life expectancy. Proposition 3(a) implies that the outcomes from maximizing $I(W)$ and $I(w, W)$ are in general different. However, since optimization always implies $c^{*}=C_{\min }$ in both cases, the only difference between the allocations is in the division of education and health expenditures towards education and health outcomes. This allocation should be done on the basis of the parameter $W$ that weighs these two arguments. It should not depend through the constraints on another parameter $w$ that is independent of these arguments in the objective function. In the development plans, income does not fulfil its intended role of securing "command over resources to enjoy a decent standard of living". This suggests that income plays no useful role in the HDI. In the absence of a replacement for an income argument in the HDI, the human development index is better specified as $I(W)$.

\section{HDI Rankings of Nations}

The propositions have positive and normative implications for how the HDI ranks countries. First consider, two nations that are identical in every respect except policy. The country with the higher HDI will be the one that is doing a better job of maximizing the HDI. However, if we take the stance that $I(W)$ is the better development index, then we can only immediately say that country with the higher HDI is doing a better job of improving human development in the special case 
$f_{l}=f_{e}=0$ where weight $w$ is irrelevant to optimal plans. Otherwise, we must we must somehow control for the bias induced when $w>0$.

Now consider countries that are only different according to multifactor productivity (e.g. $y=Z f(e, l)$, where $Z$ is multifactor productivity). If all countries were optimizing their HDI, then the country that has a greater multifactor productivity would also have the greater HDI. Indeed, since the relationship is monotonic, the ranking of countries by HDI and ranking by $y$ would be identical. Thus, under our assumptions, we get the prediction that the "development gap ranking", the rank of GDP per capita less the rank of HDI, should be zero. ${ }^{12}$

Again, however, if $I(W)$ is considered the better development index, we cannot be immediately assured that higher income that leads to a higher HDI ranking is promoting development. In principle it is possible that more wealth can lead to worse outcomes when the incorrect objective function is being optimized. By similar reasoning we also cannot be generally assured that a reduction in the development gap ranking is promoting development. This is because the correct development gap ranking involves using the rank of $I(W)$ rather than the ranking of $I(w, W)$.

\section{Modified Human Development Indexes that Avoid the Critique: Calculation and Comparison with the HDI}

This section proposes two indexes that are minimal modifications of the HDI that are not subject to the above critiques of the income component in the index. We construct and calculate these two modified indexes and then compare their ranking with those of the HDI.

The first modified index we propose is the alternative index $I(W)$, which is constructed by simply dropping the income component from the HDI. We argued in the previous section that this was a better index than the HDI. Dropping the income component avoided the double counting problem. At the same time, there was no loss from dropping the income component because it played no role but problematically

\footnotetext{
${ }^{12}$ This statistic is reported in the last column in the HDI statistics pages of the Human Development Reports.
} 
biasing the development plans between the education and health components. Whereas $I(W)$ does not suffer from the income critique, it otherwise has similar features as satisfies Propositions 1 and 2 for the special case $w=0$. Thus, we suggest it dominates the HDI.

Whereas $I(W)$ may yield a better index than the current HDI, it neglects the dimension of "command over resources to enjoy a decent standard of living". A simple way to represent this dimension and at the same time avoid the income critique is to replace the income variable with a "net income" variable that removes the elements (education and health) that are double counted. ${ }^{13}$ Net income, defined as income less expenditures on education and health, is a variable that captures the net command over resources for all other purposes than those already represented in the index.

In the our basic model, net income is the same as total consumption, $l c=y-(E+H)$, i.e. expenditures on all other items other than education and health. When either $l c$ or $c$ is used instead of income in the objective function, the Proposition 1 result that $c=c_{\min }$ no longer necessarily obtains. By putting reasonable economic structure on the problem (i.e. concave objective function and convex constraints), it is straightforward to establish an internal solution $c>c_{\min }$, where the planner trades off expenditures on education and health for more net income, is the more likely optimal outcome. ${ }^{14}$

Whereas using net income in a modified index can yield internal solutions, it can also yield outcomes that are less equitable. This is because when optimal average consumption is above the minimum, $c^{*}>c_{\min }$, there is room for dispersion of consumption. For example, it is possible for half of individuals to be at the minimum and the other half to be at $c^{*}+\left(c^{*}-c_{\min }\right)$. This possibility is not possible under the HDI or $I(W)$ criteria as optimal plans require average consumption to $c^{*}=c_{\min }$ forcing

\footnotetext{
${ }^{13}$ Recall that double counting arose because the optimal plan resulted in increases in the income component being matched by increases in education and health expenditures. As these expenditures are the inputs into the education and life expectancy indexes, the income component indirectly emphasized education and life expectancy.

${ }^{14}$ For example, the current HDI uses $\ln (\mathrm{GDP} / \mathrm{capita})$ as a variable in the index. Replacing this with $\ln (c)$ would yield sufficient concavity to generate an internal solution as long as $C_{\min }$ were not too large. Indeed, if one interpreted the lower bound of $\$ 100$ of $y$ in the index as the lower bound for $c$, almost all countries would be at an internal optimum (when the education and health achievement functions were responsive to expenditures).
} 
all individual consumption to also be at the same level, $c_{\min .}{ }^{15}$ When inequality is a concern, our modified HDI with net income should perhaps be further modified to incorporate distribution information (e.g. Gini coefficient). In our calculations below we concentrate on the examining the $I(W)$ index and leave inequality adjustments for future work. ${ }^{16}$

\section{Constructing, Calculating and Comparing the Modified HDIs with the HDI}

Constructing the $I(W)$ index is straightforward for a comparison with the HDI. We simply set $W=.5$ and use the education and health sub-indexes that are contained in the HDI. Table 1 below lists the value of the $I(W=.5)$ index, denoted HDIW. The table covers OECD nations for the year 2005 (available in the Human Development Report 2007). There is a substantial difference in the rankings of the HDIW with the HDI. ${ }^{17}$ The specific country differences are captured by "Rank of HDI less Rank of HDIW" (in the second to last column of Table 1).

It is most instructive to look at the out of the top 25 HDI ranked OECD nations since 23 of them are in the top 25 of the overall ranking of nations. From the top 25 OECD countries, the notable losers are Luxembourg, Ireland, and the US which fall by 7, 8 and 11 places respectively, whereas, Italy, Spain and New Zealand gain 6, 7 and 14 places. From the perspective of the model, the fact that the HDIW index ranking is quite different suggests that income matters. As income matters only when it is problematic in the theory, the case for using HDIW over HDI is more compelling.

(Table 1 here)

\footnotetext{
${ }^{15}$ This analysis contrasts inequality under alternative optimal plans. The scope for differences in measured inequality between plans is perhaps less when the reduction in consumption must be incremental and the status quo is far from the optimum. As described in Proposition 2, incremental changes under the HDI criterion can leave substantial inequalities. When only incremental improvements are possible using any of the criteria HDI, $I(W)$, or the modified HDI with net income leaves substantial scope for inequality.

${ }^{16}$ Anand and Sen (2000) and Foster et al (2005) provide explanations and references to ways to include inequality aversion for income directly in the HDI . In principle the very same methods could be used with our net income variable. However, in practice, there are many nations for which we lack of data with which to construct a net income variable at the individual level.

${ }^{17}$ The Spearman rank correlation coefficient (see Rao (1973)) between these two series is .9102, which indicates imperfect correlation. Given that $2 / 3$ of the HDI is perfectly correlated with HDIW and that the nations out of the top 25 are substantially different from each other (rank well down in the complete list of countries), the value of .9102 suggests that there is a substantial difference between the rankings.
} 
We denote the modified index with net income as HDIN. Constructing HDIN involves specifying the net income variable and then defining a net income sub-index. In keeping with our minimalist approach we base net income on the income (denoted $y$ below) in the HDI, i.e. GDP per capita measured in purchasing power parity equivalent dollars. We adjust this series to net out the percentage of GDP spent on private and public expenditures for education and health. The data for health is available in Table 6 of the Human Development Report 2007, and the data on education is available in Education at a Glance 2007, an OECD publication. ${ }^{18} \mathrm{We}$ have limited our analysis to OECD countries as it was difficult to find data for private education expenditures for other countries and this component is perhaps important, particularly in poorer countries many of which do not have much public provision of education.

To construct a sub-index for net income, we follow the methodology for the income sub-index in the HDI, which is constructed as follows:

$$
I^{y}(\mathrm{y})=\frac{\log (\mathrm{y})-\log (100)}{\log (40000)-\log (100)}
$$

This "achievement" sub-index uses "goalposts" $\$ 100$ as a lower bound and $\$ 40,000$ as an upper bound on income. The form of the index and the choice of goalposts have varied over the years (as described by Anand and Sen (2000)). The logarithm of income ensues that there is considerable concavity for this sub-index. In contrast, the other indexes for education and health are linear in their variables. The reason for this

\footnotetext{
${ }^{18}$ Both health and education data are a percentage out of GDP for 2004. We assume this percentage has not changed substantially for 2005. Much of the data is from lagged studies. To construct the series we use some data found in Education at a Glance 2006. Data for Luxembourg includes only public nontertiary education, and data for Estonia and the Russian Federation includes only public education expenditures.
} 
specification was to de-emphasize income to alleviate the concerns discussed in the previous section.

For net income, denoted $y^{N}$, we use the following sub-index:

$$
I^{y}\left(\mathrm{y}^{N}\right)=\frac{\log \left(\mathrm{y}^{N}\right)-\log (86)}{\log (34317)-\log (86)} .
$$

Here we have deflated the lower and upper bound valued by the factor .86 . This factor corresponds to the average net income over average income across countries. We choose this adjustment as it is in the spirit of the income index and works from the previous bounds in a way that roughly maintains the same overall weight as the income index. It is important to control for the weight otherwise that factor would be driving the differences with the HDI. With this index, Norway and Luxembourg are at the upper bound. The income index has these two countries and also the United States at the upper bound. All the countries are well away from the lower bound.

Though there is substantial variation in our net income series, it does not show up strongly in changing the rankings of net income relative to income. The largest shift is the United States, which loses 3 places. ${ }^{19}$ The lack of change in the sub-index shows up in the values and ranking of HDIN in Table 1. The difference in the ranking of this series with HDI is listed in the last column. There are relatively few differences and the largest difference is again the United States, which looses 2 places.

Clearly of our two modified indexes, the change in rankings with the HDIW is much larger than with the HDIN. This surprised us somewhat. The HDIW contains education and life expectancy and so is a subset of the HDI. Many of the OECD

\footnotetext{
${ }^{19}$ These calculations are available in a spreadsheet upon request.
} 
countries have education scores that are at or very near the upper bound. Similarly the life expectancy is high in these countries. We did not think there that the variation near the top of the indexes would drive large relatively changes in the rankings. Conversely, the variation in net income is not insubstantial and we thought this would provide a quite different ranking even though net income is near the upper bound for many OECD countries. It would appear that a key factor that is driving the results is that the logarithmic concavity of the (net) income index and the linearity of the education and life expectancy indexes. Here the lower bound on (net) income appears to be a particularly strong determinant as it much smaller than the minimum in the series. $^{20}$

To our mind using net income in a modified index like HDIN is important because it includes the additional dimension of command over resources. However, using a methodology to create the net income index that is close to that for the income index HDI yields only minor changes. This methodology appears to be deliberately intended to de-emphasize (net) income. This perspective perhaps should be reconsidered if net income is used. The fact that the HDIN series is different in the past is not substantially different is not reason for using an improved net income based index for the future.

\section{Conclusion}

The HDI is a widely cited statistic that is commonly used as a measure of well being in different countries. Here, we have examined some of the implications that follow if government planners decide to use maximization of the HDI as a criterion for optimal plans. We have found that, if they do so, planners will tend to heavily emphasize expenditures on education and health by lowering consumption. This eventually leads the economy towards a more egalitarian allocation - even though inequality aversion does not appear explicitly in the HDI itself.

\footnotetext{
${ }^{20}$ In the income sub-index the lower bound is $\$ 100$ and the net income lower bound is $\$ 86$. Contrast this with Brazil, which has the lowest income at $\$ 8,407$ and net income at $\$ 7,338$. The 25 ranked OECD country has income $\$ 22,275$ and net income $\$ 18,933$.
} 
A more problematic feature of the optimal plan is that the income component in the HDI only plays a role indirectly in determining the trade-off between expenditures on education and health. The income component effectively double counts education and health achievements, components that are already in the HDI. Because the income component does not play its intended role of securing resources for a decent standard of living, we argue that it is better to drop income from the index in considering optimal plans rather than using the HDI in its current form.

While dropping income from the HDI is a better basis for human development planning, this approach falls short of the original intent that the HDI cover dimensions beyond education and health. We consider net income, income net of education and health expenditures, as an indicator of capabilities not already reflected in the education and life expectancy components of the index. When net income is used in a modified HDI index, the optimal plan captures the direct trade-offs between allocations for consumption, education and health. This yields a balance of expenditures on the three components.

Using data OECD countries we construct and calculate two modified human development indexes, one with a net income component and another without any kind of income component. The rank ordering of nations given by these modified indexes is compared with the HDI. Interestingly, the modified index without any income component yields a far greater change in rankings. Our theory suggests that this might be because the income component in the HDI is problematic. In developing the modified index with net income we use a very similar methodology to that used in constructing HDI income sub-index. We attribute the lack of change in the ranking using this modified index to the methodology of constructing the sub-index rather than a deficiency in the net income variable or general approach to correcting the index.

In this paper we have taken the somewhat unusual methodological approach of evaluating a well-known achievement index, the HDI, in terms of the optimal plans it implies. We believe this approach has been quite revealing in uncovering unintended negative consequences of using the index for basis for making improvements. The critique of the optimal plans implied by the index lead us to modify the index in 
several ways that no longer yielded the unintended consequences. We selected amongst the alternative modified indexes according to the one that best fulfilled the original intent in creating the HDI.

The analysis of planning with multi-dimensional objectives is inherently complex. This is particularly so when there are unusual objective arguments like life expectancy which feedback to production and other elements of the economy. We have explored the implications of optimal plan with the HDI in the simplest possible environment to get a feel for the issues. Whereas we believe we that our simplistic approach has shed significant light on the questions we raise, our analysis falls short in a number of ways. Our static normative analysis in particular ignores capital accumulation and growth issues. Further we do not directly examine the positive issues around incentive and participation constraints. We intend to pursue the implications of development planning under various objectives in richer model in future research. 


\section{References}

Anand, S. and A. Sen, 2000, The income component of the human development index, Journal of Human Development, 83-106.

Anand, S. and M. Ravillion, 1993, Human development in poor countries: on the role of private incomes and public services, Journal of Economic Perspectives 7, 133-150.

Bourguignon, F. and G. Fields, 1990, Poverty measures and anti-poverty policy, Recherches Economiques de Louvain 56 (3-4), 409-427.

Budget of India, 2005, http://indiabudget.nic.in/es2004-05/chapt2005/chap14.htm.

Chrétien, J., 1998, in Former Prime Minister's Newsroom Archive (1995-2003)), $\begin{array}{llll}\text { September } & 9 & \text { 9 } & \text { http://www.pco- }\end{array}$ bcp.gc.ca $/$ default.asp? Language $=E \& P a g e=$ pmarchive $\& S u b=$ newsreleases $\& D o c=n e w$ s re19980909828 e.htm.

Deaton, A., 2003, Health, inequality, and economic development, Journal of Economic Literature XLI, 113-157.

Education at a Glance 2007, OECD, www.oecd.org/edu/eag2007

Foster, J., L. Lopez-Calva, and M. Szekely, 2005, Measuring the distribution of human development: methodology and an application to Mexico, Journal of Human Development 6, 5-25.

Kalam, A., 2005, address at the: International seminar on income and employment security in India", April 6, 2005, New Delhi Index. http://presidentofindia.nic.in/scripts $/$ sllatest1.jsp?id=502.

Osberg, L. and A. Sharpe, 2005, How should we measure the "economic" aspects of well-being?, Review of Income and Wealth, 51(2), 311-336. 
Parsai, G., 2006, India one notch up in its Human Development Index, The Hindu, October 11, 2006,

http://www.thehindu.com/2006/11/10/stories/2006111018392400.htm

Rao, C. R., 1973, Linear Statistical Inference and Its Applications, John Wiley \& Sons, New York.

Sen, A. K., 1981, Public action and the quality of life in developing countries, Oxford Bulletin of Economics and Statistics 43, 287-319.

Sen, A. K., 1985, Commodities and capabilities (North-Holland, Amsterdam).

\section{APPENDIX}

Proof to Proposition 1. The Lagrangian for problem (P1) is:

$$
\begin{aligned}
L_{H D I}= & w I^{y}(f(l(E, H), e(E, H)))+(1-w)\left(W I^{e}(e(E, H))+(1-W) I^{l}(l(E, H))\right) \\
& +\lambda_{1}(f(l(E, H), e(E, H))-E-H-l(E, H) c)+\lambda_{2}\left(c-c_{\text {min }}\right)
\end{aligned}
$$

Among the Kuhn-Tucker conditions for are the following:

$$
\begin{gathered}
c\left(\lambda_{2}-\lambda_{1} l(E, H)\right)=0 \\
\lambda_{2}\left(c-c_{\text {min }}\right)=0 \\
\lambda_{1} \geq 0, \quad \lambda_{2} \geq 0
\end{gathered}
$$

We now show that at an optimum $\lambda_{2}>0$. Suppose not. Then, by (10), $\lambda_{2}=0$. By (8), since $l(E, H)>0$ and $c>0$, this implies that $\lambda_{1}=0$. Since the objective function is strictly increasing in $E$ and $H$, the resource constraint (6) binds, and so $\lambda_{1}>0$. This is a contradiction. Thus, $\lambda_{2}>0$. By (9), this then implies that $c=c_{\min }$. It remains to check the constraint qualification when constraint (ii) in problem (P1) is not binding. If (i) is also not binding the constraint qualification is trivially satisfied. If (i) is binding then the gradient vector to (i) is $\nabla \mathrm{g}_{1}(c, E, H)=\left(l, l_{E} c+1-f_{l} l_{E}-f_{e} e_{E}, l_{H} c+1-f_{l} l_{H}-f_{e} e_{H}\right)$ for $c>c_{\min }$. When there is only one vector, it is linear dependent only if $\nabla g_{1}(c, E, H)=(0,0,0)$. The 
assumption in $(3), l(0,0)>0$, rules this out. Even without this assumption, the gradient must be linearly independent. A necessary condition for linear dependence is $l_{E} c+1-f_{l} l_{E}-f_{e} e_{E}=0$. But this condition cannot correspond to local maximum because decreasing $c$ to increase $\mathrm{E}$ and/or $\mathrm{H}$ along the constraint increases the objective function. Hence, the constraint qualification is satisfied and the KuhnTucker conditions are necessary for a maximum. Thus, at an optimum $c^{*}=c_{\min }$.

Suppose policy limits the level to which consumption can be reduced to some level $c_{p}$ , where $c_{p}>c_{\min }$. Then the planner's problem yields a Lagrangian that is the same as (7) except for $c_{p}$ replacing $c_{\min }$. As above $\lambda_{2}>0$. Thus, the marginal value of restricting the policy level $c_{p}$ further is $\frac{d L_{H D I}}{d c_{p}}=-\lambda_{2}<0$. It follows that reductions in $c_{p}$ increase the Lagrangian, which is just the constrained optimal HDI score.

Proof to Proposition 2. The Lagrangian for this problem is:

$$
\begin{aligned}
\mathbf{L}_{\mathbf{H D I}}= & \left.w I^{y}(f(l, e))+(1-w)\left(W I^{e}(e)+(1-W) I^{l}(l)\right)\right) \\
& +\lambda_{1}\left(f(l, e)-E-H-\sum_{i=1}^{N} l_{i} c_{i}\right)+\sum_{i=1}^{N} \lambda_{2 i}\left(c_{i}-c_{\text {min }}\right)
\end{aligned}
$$

Among the Kuhn-Tucker conditions for are the following:

$$
\begin{gathered}
c_{i}\left(\lambda_{2 i}-\lambda_{1} l_{i} / N\right)=0 \\
\lambda_{2 i}\left(c_{i}-c_{\min }\right)=0 \\
\lambda_{1} \geq 0, \quad \lambda_{2 i} \geq 0
\end{gathered}
$$

(a) This is a generalization of the proof to Proposition 1 and is identical except for having to show that $\lambda_{2 i}>0$ for all $i$ at an optimum.

(b) The incremental result with respect to average consumption is also a generalization Proposition 1 but with individual values of $c_{p i}>c_{\min }$. The possibility of increasing inequality is demonstrated in the text. 
(c) Given the strict concavity of the attainment functions $e_{i}$ and $l_{i}$, it follows that the Lagrange multipliers corresponding to $E_{i}$ and $H_{i}$ must be the same across individuals which requires equal allocations and outcomes.

\section{Proof to Proposition 3.}

(a) By Proposition 1, $c=c_{\min }$. Problem P1 is therefore equivalent to the following problem, P2, which determines the choices of $E$ and $H$ :

$\operatorname{Max}_{\{E, H\}} I\left(w, W, C_{\min }\right)=w I^{y}(f(l(E, H), e(E, H)))+(1-w)\left(W I^{e}(e(E, H))+(1-W) I^{I}(l(E, H))\right)$ subject to: $\quad l(E, H) c_{\min }+E+H-f(l(E, H), e(E, H)) \leq 0$

(b) Consider an alternative objective function where only the indexes $I^{e}(e)$ and $I^{l}(l)$ have weight: $I(\hat{W})=\hat{W} I^{e}(e(E, H))+(1-\hat{W}) I^{l}(l(E, H))$. When $f_{l}=f_{e}=0$ then $I(w, W)$ is simply an affine transformation of $I(W)$ 
Table 1

\begin{tabular}{|c|c|c|c|c|c|c|c|c|}
\hline \multirow[b]{2}{*}{ Country } & \multicolumn{3}{|c|}{ Human Development Indexes } & \multicolumn{3}{|c|}{ Rank of HDI Indexes } & \multicolumn{2}{|c|}{ Rank Differences } \\
\hline & $\begin{array}{l}\text { HDI } \\
\text { (Original } \\
\text { 2005) }\end{array}$ & $\begin{array}{l}\text { HDIW } \\
\text { (HDI } \\
\text { Without } \\
\text { Income) }\end{array}$ & $\begin{array}{l}\text { HDIN } \\
\text { (With Net } \\
\text { Income) }\end{array}$ & $\begin{array}{l}\text { Rank of } \\
\text { HDI (in } \\
\text { OECD) }\end{array}$ & $\begin{array}{l}\text { Rank of } \\
\text { HDIW }\end{array}$ & $\begin{array}{l}\text { Rank of } \\
\text { HDIN }\end{array}$ & $\begin{array}{l}\text { Rank of } \\
\text { HDI less } \\
\text { Rank of } \\
\text { HDIW }\end{array}$ & $\begin{array}{l}\text { Rank of } \\
\text { HDI less } \\
\text { Rank HDIN }\end{array}$ \\
\hline Iceland & 0.968 & 0.960 & 0.966 & 1 & 2 & 2 & -1 & -1 \\
\hline Norway & 0.968 & 0.952 & 0.968 & 2 & 6 & 1 & -4 & 1 \\
\hline Australia & 0.962 & 0.963 & 0.961 & 3 & 1 & 3 & 2 & 0 \\
\hline Canada & 0.961 & 0.956 & 0.960 & 4 & 3 & 5 & 1 & -1 \\
\hline Ireland & 0.959 & 0.942 & 0.960 & 5 & 13 & 4 & -8 & 1 \\
\hline Sweden & 0.956 & 0.951 & 0.955 & 6 & 7 & 6 & -1 & 0 \\
\hline Switzerland & 0.955 & 0.942 & 0.953 & 7 & 12 & 8 & -5 & -1 \\
\hline Japan & 0.953 & 0.951 & 0.954 & 8 & 9 & 7 & -1 & 1 \\
\hline Netherlands & 0.953 & 0.946 & 0.952 & 9 & 11 & 9 & -2 & 0 \\
\hline France & 0.952 & 0.951 & 0.950 & 10 & 8 & 11 & 2 & -1 \\
\hline Finland & 0.952 & 0.946 & 0.952 & 11 & 10 & 10 & 1 & 1 \\
\hline United States & 0.951 & 0.926 & 0.948 & 12 & 23 & 14 & -11 & -2 \\
\hline Spain & 0.949 & 0.956 & 0.950 & 13 & 4 & 12 & 9 & 1 \\
\hline Denmark & 0.949 & 0.938 & 0.948 & 14 & 15 & 13 & -1 & 1 \\
\hline Austria & 0.948 & 0.937 & 0.947 & 15 & 17 & 15 & -2 & 0 \\
\hline $\begin{array}{l}\text { United } \\
\text { Kingdom }\end{array}$ & 0.946 & 0.935 & 0.946 & 16 & 18 & 16 & -2 & 0 \\
\hline Belgium & 0.946 & 0.937 & 0.945 & 17 & 16 & 17 & 1 & 0 \\
\hline Luxembourg & 0.944 & 0.916 & 0.944 & 18 & 25 & 18 & -7 & 0 \\
\hline New Zealand & 0.943 & 0.953 & 0.942 & 19 & 5 & 19 & 14 & 0 \\
\hline Italy & 0.941 & 0.940 & 0.942 & 20 & 14 & 20 & 6 & 0 \\
\hline Germany & 0.935 & 0.928 & 0.934 & 21 & 22 & 21 & -1 & 0 \\
\hline Israel & 0.932 & 0.934 & 0.930 & 22 & 20 & 22 & 2 & 0 \\
\hline Greece & 0.926 & 0.934 & 0.928 & 23 & 19 & 23 & 4 & 0 \\
\hline $\begin{array}{l}\text { Korea } \\
\text { (Republic of) }\end{array}$ & 0.921 & 0.931 & 0.922 & 24 & 21 & 24 & 3 & 0 \\
\hline Slovenia & 0.918 & 0.926 & 0.918 & 25 & 24 & 25 & 1 & 0 \\
\hline Portugal & 0.897 & 0.902 & 0.896 & 26 & 26 & 26 & 0 & 0 \\
\hline $\begin{array}{l}\text { Czech } \\
\text { Republic }\end{array}$ & 0.891 & 0.892 & 0.892 & 27 & 29 & 27 & -2 & 0 \\
\hline Hungary & 0.875 & 0.879 & 0.875 & 28 & 30 & 28 & -2 & 0 \\
\hline Poland & 0.872 & 0.896 & 0.873 & 29 & 28 & 29 & 1 & 0 \\
\hline Chile & 0.867 & 0.901 & 0.868 & 30 & 27 & 30 & 3 & 0 \\
\hline Slovakia & 0.862 & 0.871 & 0.864 & 31 & 32 & 32 & -1 & -1 \\
\hline Estonia & 0.862 & 0.872 & 0.864 & 32 & 31 & 31 & 1 & 1 \\
\hline Mexico & 0.829 & 0.853 & 0.830 & 33 & 33 & 33 & 0 & 0 \\
\hline $\begin{array}{l}\text { Russian } \\
\text { Federation }\end{array}$ & 0.803 & 0.813 & 0.806 & 34 & 35 & 34 & -1 & 0 \\
\hline Brazil & 0.800 & 0.830 & 0.801 & 35 & 34 & 35 & 1 & 0 \\
\hline Turkey & 0.775 & 0.793 & 0.777 & 36 & 36 & 36 & 0 & 0 \\
\hline
\end{tabular}

